pag

Business School

WORKING PAPER SERIES

Working Paper 2014-080

\section{Responses of international stock} markets to oil price surges: a regimeswitching perspective

Rania Jammazi

Duc Khuong Nguyen

http://www.ipag.fr/fr/accueil/la-recherche/publications-WP.html

IPAG Business School

184, Boulevard Saint-Germain

75006 Paris

France 


\title{
Responses of international stock markets to oil price surges: a regime- switching perspective
}

\author{
Rania Jammazi \\ International finance group-Tunisia \& University of Sousse, B.P. 307, Cité Erriadh, 4023, Sousse, Tunisia \\ E-mail: jamrania2@yahoo.fr \\ Duc Khuong Nguyen \\ Department of Finance and Information Systems, ISC Paris School of Management, 22 Boulevard du Fort de \\ Vaux, 75017 Paris, France \\ dnguyen@iscparis.com
}

\begin{abstract}
We propose an enhanced regime-switching model to investigate the relationships between oil price surges and stock market cycles in five oil-dependent countries over the period from January 1989 to December 2007. Our model accounts for the joint effects of the WTI (West Texas Intermediate) and Brent oil markets and allows to simultaneously capture asymmetry, volatility persistence and regime shifts contained in the underlying financial data. We find that stock market returns strongly exhibit a regime-switching behavior, but they react differently to the increases in the price of oil. More precisely, the conditional volatility of studied stock markets during the bear market phases is found to be less affected by oil price shocks than during the bull market phases. Whether the effects of oil shocks are positive and negative depends greatly on the degree of reliance on imported oil, the share of the cost of oil in the national income and the degree of improvement in energy efficiency of a given country. Finally, the relatively opposite effects of the WTI and Brent oil markets suggest the potential of substitution between them as well as the necessity of a diversification strategy of oil supply sources.
\end{abstract}

Keywords: oil price shocks, stock market cycles, regime-switching model JEL classification: C58; F30; G15 


\section{Introduction}

The analysis of crude oil price shocks on macroeconomic variables has received considerable attention from academic researchers, investors and policymakers following the 1970s oil crisis. Using Granger causality tests, Hamilton (1983) shows that rising oil prices are responsible for nine out of ten of the U.S. recessions since the Second World War, thus suggesting a negative impact of oil price changes on U.S. output growth. A number of subsequent studies, using various methodologies and different datasets, reach similar conclusions and explain the oilgrowth relationship by the oil price effects on production cost, inflation expectation, monetary policy, and investor confidence (Mork, 1989; Bachmeier, 2008; Cologni and Manera, 2008). For example, Mork (1989) extends Hamilton (1983)'s results by investigating the effects of both upward and downward oil price movements on GDP growth. Mork finds that oil price increases impeded economic growth but oil price decreases did not appear to boost growth during the post-Second World War period, thus highlighting the asymmetric responses of growth to oil price increases and decreases. Some recent attempts such as Hamilton (2003), Kilian (2008), Zhang (2008), Lardic and Mignon (2008), and Cologni and Manera (2009) confirm the asymmetric pattern and also document nonlinear links between oil price shocks and growth (and other macroeconomic variables). Another important finding of this literature is that the oil price - output relationship is weakening in the United States and some other oilimporting countries, especially during the recent decades and precisely after the 1986 oil price collapse (Hamilton, 1996, 2003; Blanchard and Gali, 2007; Kilian, 2008; Balke et al., 2009). ${ }^{1}$

The extent to which stock markets around the world are affected by oil price movements has only been investigated recently. As oil price increases are found to negatively affect real output, the rise in the price of oil would expectedly cause the stock prices to decline owing to higher business operating costs and lower corporate earnings. ${ }^{2}$ This theoretical prediction is firstly confirmed by an important empirical study of Jones and Kaul (1996) who report a significant negative impact of crude oil shocks on stock market returns in two out of four major developed countries (Canada and the United States). Sadorsky (1999), Papapetrou (2001), and Ciner (2001) provide evidence to support the Jones and Kaul (1996)'s initial findings.

\footnotetext{
${ }^{1}$ Kilian (2008) further notes that energy price shocks do not exert a significant impact on the U.S. economy, and that oil shocks appear to be among many contributing factors of the U.S. recession but not a robust determinant. See also Mory (1993) and Hondroyiannis et al. (2001) for discussions on how oil prices can affect other various macroeconomic variables including interest rates, export, import, and government expenditure.

${ }^{2}$ Cong et al. (2008), Nandha and Faff (2008), and Narayan and Sharma (2011) examine the relationship between oil prices and firm returns of different countries, and find strong dependence between these two variables. Arouri et al. (2011) examine the volatility transmission between oil and sector stock markets.
} 
However, the above-mentioned negative relationship does not always hold when more recent datasets are considered. Using data from stock markets of six OECD countries over the period 1971-2008, Miller and Ratti (2009) provide evidence of a robust negative long-run link between oil price increases and stock market returns, but this link disappears after September 1999. Bubbles in asset markets and/or crude oil markets may, according to the authors, be responsible for this instable relationship. Jammazi and Aloui (2010) find similar results for three developed markets (France, Japan, and United Kingdom) while making use of wavelet and MS-VAR model (Markov-switching Vector Autoregressions). The negative relationship also appears to be more pronounced during the pre-1999 period. Moreover, while some recent studies find convincing evidence of positive impact of crude oil changes on stock market returns (El Sharif et al., 2005; Narayan and Narayan, 2010; Ono, 2011), the others document weak evidence that crude oil prices affect stock market returns in either a positive or negative way (Huang et al., 1996; Maghyereh, 2004; Cong et al., 2008; Apergis and Miller, 2009; Al Janabi et al., 2010). ${ }^{3}$ These mixed results can be explained by the heterogeneous degree of oil dependence that exists among sample markets. For instance, Park and Ratti (2008) demonstrate that stock market responses to an oil shock depend on whether the considered country is a net importer or a net exporter of oil. The sign of stock market reaction may also differ greatly depending on the origin of oil price increases, i.e., the aggregate demand/precautionary demand shock or supply shock (Kilian and Park, 2009). Aloui et al. (2012) show that market's oil-dependence profile matter for the reaction of stock return and that the oil risk is prevailing for markets exhibiting positive correlation with oil returns.

Another important concern of the related literature is the potential of asymmetries and nonlinearities that may characterize the oil-stock market relationship. Not only stock markets react differently to oil price increases and decreases, but oil shocks can cause different effects on stock returns depending on whether stock markets are on bearish and bullish states. More importantly, the accurate modeling of the links between oil and stock markets should not underscore the regime-switching behavior of return series. As to stock returns, Turner et al. (1989) and Chu et al. (1996) apply Markov-switching autoregressive models (MS-AR) and find strong evidence of regime-switching behavior. Based on a parsimonious regime switching model, and Maheu and McCurdy (2000) also document the existence of a high-return sta-

\footnotetext{
${ }^{3}$ Several studies address the relationship between oil prices and stock returns at the sector level (Boyer and Filion, 2007; El-Sharif et al., 2005; Nandha and Faff, 2008; Nandha and Brooks, 2009; Arouri and Nguyen, 2010). Overall, they show that the reaction of sector returns to changes in oil prices differs sensitively across sectors and that the presence of the oil assets in a portfolio of sector stocks permits to improve the portfolio's risk-return characteristics.
} 
ble state (bull market) and low-return volatile state (bear market) for monthly U.S. stock market returns. Regime shifts have also been found in the dynamics of conditional volatility of stock returns (Cai, 1994; Hamilton and Susmel, 1994; Diamantis, 2008; Chang, 2009). Concerning the oil markets, several studies have concluded that regime switches and asymmetric volatility play a decisive role in forecasting returns, volatility and tail distributions of crude oil returns (Fong and See, 2002; Vo, 2009; Chang, 2012). Taken together, these findings suggest the relevance and usefulness of regime-switching models in exploring the dynamic interactions between oil prices and stock market returns.

In this article we also address the issue of oil-stock market interactions by extending the existing literature in several ways. We first investigate the reaction of international stock markets in five developed countries (Canada, Germany, Japan, United Kingdom and United States) to oil price increases using a two-regime MS-EGARCH model, introduced by Henry (2009). Recent empirical studies have confirmed that this model allows for a better description of the underlying data of stock and commodity returns given its ability to simultaneously capture asymmetry, persistence as well as regime shifts (Chkili et al., 2012; Chang, 2012). For example, Chang (2012) uses MS-EGARCH model with Student- $t$ distributed error terms to investigate whether information regarding regime-switching property can affect the behavior of crude oil futures returns. He finds that the model generates accurate forecasts and provides great flexibility in fitting the basic distribution of the data. Second, we focus on testing the predictive power of both WTI and Brent oil prices for stock market returns. The simultaneous consideration of the effects from the two crude oil benchmarks is of particular interest in the sense that it guarantees a more realistic representation of the global oil market. ${ }^{4}$ Finally, while most of the existing studies tend to distinguish between positive and negative variations of oil prices (e.g., Basher and Sadorsky, 2006; Sadorsky, 2008; Nandha and Faff, 2008), we employ a more refined nonlinear oil price measure proposed by Hamilton (1996), namely the net oil price increase (NOPI). Here our motivations regarding the use of NOPI are twofold. On the one hand, there is lack of consensus on the effect of the oil price variations (hikes and falls) on the stock markets, and thus a new research in this direction is not necessary. On the other hand, besides the asymmetric reaction of international stock market returns to oil price in-

\footnotetext{
${ }^{4}$ Hammoudeh et al. (2008), among others, examine the asymmetric adjustment process between four crude oil benchmark prices (WTI, Brent, Dubai, and Maya). Their results indicate that the WTI and Brent markets are much more liquid and have stronger leadership stature than the Dubai and Maya benchmarks. More interestingly, these benchmark prices adjust to a common equilibrium in the long run, regardless of their properties and physical locations.
} 
creases and decreases, past studies agree, at least to some extent, that the effects of oil price increases are more important than those associated with oil price decreases (Bjørnland, 2009).

The remainder of this article is organized as follows. Section 2 describes the data and introduces the Markov-switching EGARCH framework used in this study. Section 3 presents and discusses the estimation results. Section 4 provides some concluding remarks.

\section{Data and econometric method}

\subsection{Data and variables specification}

The data consist of monthly returns on stock market indices of five major industrial countries, namely DJIA (United States), DAX30 (Germany), FTSE100 (United Kingdom), TSX (Canada), and NIKKEI225 (Japan). For crude oil, we use the monthly returns on two international price benchmarks: the West Texas Intermediate (WTI) and the Europe Brent. Our study period runs from January 1989 through December 2007 and covers months of historically high and volatile oil prices. It is worth noting that oil price movements over this period were driven not only by supply disruptions as in 1990 but also by a variety of factors including, among others, market speculations and the continued upward trend in oil demand especially from developing countries since 1999, which are typically associated with slowdowns in oil supply growth (Jammazi, 2012). Crude oil prices are extracted from the Energy Information Administration (US Department of Energy), and stock market prices are obtained from Datastream International. We compute the stock and oil returns by taking the difference in the logarithm of two successive prices.

In the literature, several proxies for oil price shocks have been developed to model the nonlinearity and asymmetry of oil price effects on stock market returns. They include, among others, the growth rate of oil prices, the increases in oil prices, the decreases in oil prices, the net oil price measure, the scaled oil prices (Lee et al., 1995; Hamilton, 1996). Following the suggestions of recent research that oil price increases have strong and negative consequences for economic, financial and industrial activities (e.g., Hamilton, 1983; Bjørnland, 2009; Sari et al., 2010), we restrict our choice of oil measure to the net oil price increase (NOPI), introduced by Hamilton (1996). This measure is constructed as the difference between the current monthly price and its highest value over the previous year if it is positive, and zero otherwise as follows 


$$
N O P I\left\{\begin{array}{l}
=o i l_{t}-\max \left(\text { oil }_{t-1}, \ldots, \text { oil }_{t-12}, \text { if } \text { oil }_{\mathrm{t}-1}, \ldots, o i l_{t-12}\right) \\
=0, \text { otherwise }
\end{array}\right.
$$

Several works have used the NOPI to analyze the relationship between oil price shocks and stock returns (Park and Ratti, 2008; Cong et al., 2008). For example, Cong et al. (2008) find that some important oil price shocks depress Chinese oil company stock prices. Hamilton (1996) notes that most increases in oil price since 1986 have been immediately followed by even larger decreases. So, it is more appropriate to compare the current price of oil with its position over the previous year rather than during the previous month alone.

\subsection{Markov-switching EGARCH model}

Let's firstly consider a standard EGARCH $(1,1)$ process introduced by Nelson (1991) as given in Eq. (2)

$$
\ln \left(h_{t}\right)=\omega_{0}+\varphi\left[\left|\frac{\varepsilon_{t-1}}{\sqrt{h_{t-1}}}\right|-\sqrt{2 / \pi}\right]+\beta \ln \left(h_{t-1}\right)+\delta \frac{\varepsilon_{t-1}}{\sqrt{h_{t-1}}}
$$

where $h_{t}$ denotes the conditional variance and is strictly positive. $\varepsilon_{t}$ is the error term from the conditional mean process. The EGARCH model is advantageous in that it does not require the imposition of non-negativity constraints as in the standard GARCH model. It further incorporates the asymmetric reaction of conditional volatility to news (shocks) affecting the system.

Lamoureux and Lastrappes (1990) argue that the high degree of persistence found in the conditional volatility of the standard GARCH model may be spurious in the presence of neglected structural breaks. Hamilton and Susmel (1994) also share this viewpoint and construct a regime switching model by modifying the conditional variance equation to make it dependent on the state of the economy. Henry (2009) extends the existing Markov-switching (MS) models to accommodate important stylized facts of financial returns such as volatility persistence, asymmetry and regime shifts. Given its modeling advantages and economic relevance, we make use of Henry (2009)'s MS-EGARCH model to examine the oil-stock market relationships.

Formally, let $r_{t}$ denote the logarithmic return on stock market index of a given country and its time-variations can be modeled by a univariate MS-EGARCH(1,1) model as follows 


$$
\left\{\begin{array}{l}
r_{t}=\mu_{i t}+\varepsilon_{t} \text { with } \varepsilon_{t} / I_{t-1} \rightarrow \operatorname{St}\left(0, h_{i t}\right) \\
\ln \left(h_{i t}\right)=\omega_{i}+\varphi_{i}\left[\left|\frac{\varepsilon_{t-1}}{\sqrt{h_{i, t-1}}}\right|-\sqrt{2 / \pi}\right]+\beta_{i} \ln \left(h_{i, t-1}\right)+\delta_{i} \frac{\varepsilon_{t-1}}{\sqrt{h_{i, t-1}}}
\end{array}\right.
$$

where $I_{t-1}$ refers to the information set containing all information available up to time $(t-1)$ and $\varepsilon_{t}$ the error term which follows a Student- $t$ distribution as in Bollerslev (1987). $\mu_{i t}$ is the state-dependent conditional mean of the return generating process. The asymmetric reaction of conditional volatility to good and bad news is captured by the coefficient $\delta$. If the estimate of $\delta$ is typically negative in sign, a negative shock to unexpected returns $\left(\varepsilon_{t}\right)$ will generate more impacts on volatility than a positive shock of the same magnitude. The model in Eq. (3) allows for the existence of two states $i$ indexed by an unobservable discrete variable $\left(s_{t}\right)$ for all $t$ whose values depend on the state of the market. In practice, $s_{t}$ takes the value of 0 when the market is characterized by low expected return and high variance (bear market regime) and the value of 1 when it is characterized by high expected return and low variance (bull market regime). Following Hamilton (1989), we assume that the transition between the states follows the first-order two-state Markov process as follows

$$
\begin{aligned}
& p\left(s_{t}=0 / s_{t-1}=0\right)=p_{00} \\
& p\left(s_{t}=0 / s_{t-1}=1\right)=1-p_{11} \\
& p\left(s_{t}=1 / s_{t-1}=0\right)=1-p_{00} \\
& p\left(s_{t}=1 / s_{t-1}=1\right)=p_{11}
\end{aligned}
$$

where $p\left(s_{t}=i / s_{t-1}=i\right)=p_{i i}$, for $i=0,1$, is the probability that the considered stock market switches from one state at time $(t-1)$ to another state at time $t$, with the following condition being held: $p_{i 1}+p_{i 2}=1$. The expected duration of the regime $i$ is given by $E(D)=1 /\left(1-p_{i}\right)$. Similar to Henry (2009), the transition probabilities are assumed to be constant over time according to a logistic function such as

$$
p_{00}=\frac{e\left(\theta_{0}\right)}{1+e\left(\theta_{0}\right)} \text { and } p_{11}=\frac{e\left(\partial_{0}\right)}{1+e\left(\partial_{0}\right)}
$$

Based on the above-described framework, we are now able to examine the oil price shocks on the regime-switching behavior of stock market returns by introducing the NOPI into the variance equation. Our extended conditional MS-EGARCH( $(1,1)$ model for stock returns take the following form 


$$
\left\{\begin{array}{l}
r_{t}=\mu_{i t}+\varepsilon_{t} \text { with } \varepsilon_{t} / I_{t-1} \rightarrow \operatorname{St}\left(0, h_{i t}\right) \\
\ln \left(h_{i t}\right)=\omega_{i}+\varphi_{i}\left[\left|\frac{\varepsilon_{t-1}}{\sqrt{h_{i, t-1}}}\right|-\sqrt{2 / \pi}\right]+\beta_{i} \ln \left(h_{i, t-1}\right)+\delta_{i} \frac{\varepsilon_{t-1}}{\sqrt{h_{i, t-1}}}+\lambda_{W i} N O P I_{t-1}+\lambda_{B i} N O P I_{t-1}
\end{array}\right.
$$

where $\lambda$ is a coefficient associated to the lagged oil variable. As a byproduct of the estimation step, we obtain the smoothed probabilities of being in the state $i$ for $i=1, \ldots, k$

$$
P\left(S_{i} / \Phi_{T}, \ldots ., \Phi_{1}\right)
$$

The smoothed probabilities are derived by using information from the entire sample $\Phi$ and are of great interest in determining if and when regime shifts have occurred.

\section{Results and discussion}

\subsection{Regime-switching behavior of stock market returns}

We begin our empirical analysis with estimating the baseline MS-EGARCH model without the NOPI variable for the six stock markets under consideration. This model is subject to regime shifts in both mean and variance structures. We report the estimation results in Table 1. The regime 0 and regime 1 correspond to the bear and bull market phases respectively.

Table 1

Estimation results of the MS-EGARCH(1,1) model without the oil price effects

\begin{tabular}{llllll}
\hline & DJIA & DAX30 & NIKKEI225 & TSX & FTSE100 \\
\hline$\mu_{0}$ & 0.37784 & $-1.24924^{* * * *}$ & $-0.91159^{* * *}$ & $-0.25224^{* * * *}$ & -1.61577 \\
$\mu_{1}$ & $(0.351)$ & $(-5.823)$ & $(-2.808)^{* *}$ & $(-8.341)^{* * *}$ & $(-0.739)$ \\
& $0.6165^{* * *}$ & $0.63298^{* * *}$ & $0.91453^{* *}$ & $1.2493^{* * *}$ & $0.5042^{* *}$ \\
$\omega_{0}$ & $(2.999)$ & $(3.9)$ & $(2.085)$ & $(14.67)$ & $(1.739)$ \\
& $2.22237^{*}$ & 0.28649 & $1.79368^{* * *}$ & $5.99203^{* * *}$ & 1.6543 \\
$\omega_{1}$ & $(3.315)$ & $(0.694)$ & $(4.239)$ & $(15.743)^{* * *}$ & $(0.667)$ \\
& $1.18188^{* *}$ & 0.02375 & $0.89308^{* * *}$ & $2.14644^{* * *}$ & 0.61872 \\
$\varphi_{0}$ & $(1.941)$ & $(0.021)$ & $(2.326)$ & $(2.7332)^{* * *}$ & $(1.077)$ \\
& $0.89865^{*}$ & $1.47123^{* * *}$ & 0.26475 & $1.24158^{* * *}$ & 0.49065 \\
$\varphi_{1}$ & $(1.152)$ & $(4.594)$ & $(0.416)$ & $(16.298)^{* * *}$ & $(0.529)$ \\
& 0.26873 & $1.17917^{* * *}$ & -0.36532 & $1.13083^{* * *}$ & $0.92476^{* * *}$ \\
$\beta_{0}$ & $(0.411)$ & $(4.241)$ & $(-0.775)$ & $(20.564)$ & $(6.869)$ \\
& 0.29626 & $0.45647^{* * *}$ & 0.42329 & $0.97043^{* * *}$ & 0.25833 \\
$\beta_{1}$ & $(0.807)$ & $(3.738)$ & $(0.977)$ & $(119.806)$ & $(0.483)$ \\
& 0.24703 & $0.6581^{*}$ & $-0.65771^{* * *}$ & $0.96423^{* * *}$ & $0.72128^{* * *}$ \\
$\delta_{0}$ & $(0.361)$ & $(1.641)$ & $(-3.383)$ & $(82.413)$ & $(7.175)$ \\
& -0.75806 & $-0.96856^{* * *}$ & 1.2107 & $-0.27834^{*}$ & -1.92325 \\
$\delta_{1}$ & $(-0.734)$ & $(-16.086)$ & $(0.668)$ & $(-1.528)$ & $(-0.359)$ \\
& 2.49648 & -0.05963 & -0.35239 & $1.13544^{* * *}$ & -1.23081 \\
$\theta_{0}$ & $(0.382)$ & $(-0.306)$ & $(-0.404)$ & $(9.902)$ & $(-0.958)$ \\
$\partial_{0}$ & $3.92429^{* * *}$ & $3.02701^{* * *}$ & $2.13317^{* * *}$ & $-1.50632^{* * *}$ & 0.55299 \\
& $(4.357)$ & $(2.964)$ & $(2.151)$ & $(-4.724)$ & $(0.194)$ \\
& $-4.88938^{* * *}$ & $-4.93297^{* * *}$ & $-1.88091^{* *}$ & $0.83105^{* *}$ & $2.1606^{*}$ \\
& $(3.952)$ & $(-4.772)$ & $(-1.395)$ & $(2.069)$ & $(1.445)$ \\
\hline
\end{tabular}




\begin{tabular}{llllll}
\hline$p_{00}$ & $0.98063[51.6 \mathrm{~m}]$ & $0.95378[21.6 \mathrm{~m}]$ & $0.89409[9.44 \mathrm{~m}]$ & $0.81851[5.51 \mathrm{~m}]$ & $0.36517[1.57 \mathrm{~m}]$ \\
$p_{11}$ & $0.99253[134 \mathrm{~m}]$ & $0.99285[140 \mathrm{~m}]$ & $0.86772[7.56 \mathrm{~m}]$ & $0.69658[3.3 \mathrm{~m}]$ & $0.89666[9.68 \mathrm{~m}]$ \\
\hline Log-Likelihood & -478.218 & -458.901 & -487.586 & -387.177 & -399.092 \\
Q(12) & 3.0323 & 12.9909 & 18.4303 & 20.5205 & 10.7036 \\
$\mathrm{Q}^{2}(12)$ & 0.0998 & 6.0577 & 11.4294 & 5.2226 & 9.7931 \\
LR & -470.07 & -458.901 & -487.586 & -387.177 & -399.092 \\
\hline
\end{tabular}

Notes: This table reports the estimation results of the MS-EGARCH $(1,1)$ model with a constant parameter $(\mu)$, and $\operatorname{ARCH}(\varphi)$, GARCH $(\beta)$ and asymmetric $(\delta)$ terms. $\theta$ and $\partial$ are the parameters of the logistic function for determining the values of the transition probabilities. The t-statistics of the estimates are reported between parentheses. $\mathrm{Q}(12)$ and $\mathrm{Q}^{2}(12)$ refer to the empirical statistics of the Ljung-Box test for autocorrelation applied to the residual and squared residuals at lag 12. Numbers in brackets represent the expected durations (expressed in months) of staying in regimes 0 and 1 .

At the first sight, Table 1 shows that all the stock market returns are characterized by negative returns during the bear market state, except for the DJIA. However, the statedependence returns are not significant for the US and UK stock markets. The lowest monthly return is found in Germany $(-1.25 \%)$, preceded by Japan $(-0.91 \%)$ and Canada $(-0.25 \%)$. The bull market regime is inversely characterized by high and significant returns in all cases. It is also easy to observe the high persistence of the two regimes in view of the transition probabilities, $p_{00}$ and $p_{11}$ (i.e., the probability of staying in the same regime) that exceed $70 \%$, except for the United Kingdom where $p_{00}$ is about 0.36 . The expected durations of staying in the bull regime appear to be much longer than the bear regime for the United States, Germany and the United Kingdom (134, 140 and 9.7 months against 51.6, 21.6 and 1.6 months), while for Japan and Canada the bear regime is found to be longer-lasting with expected durations of 9.44 and 5.51 months respectively. The quick, decisive and effective actions taken by economic authorities after an unexpected shutdown or crash may explain the persistence of the bull regime in Germany, the United Kingdom and the United States.
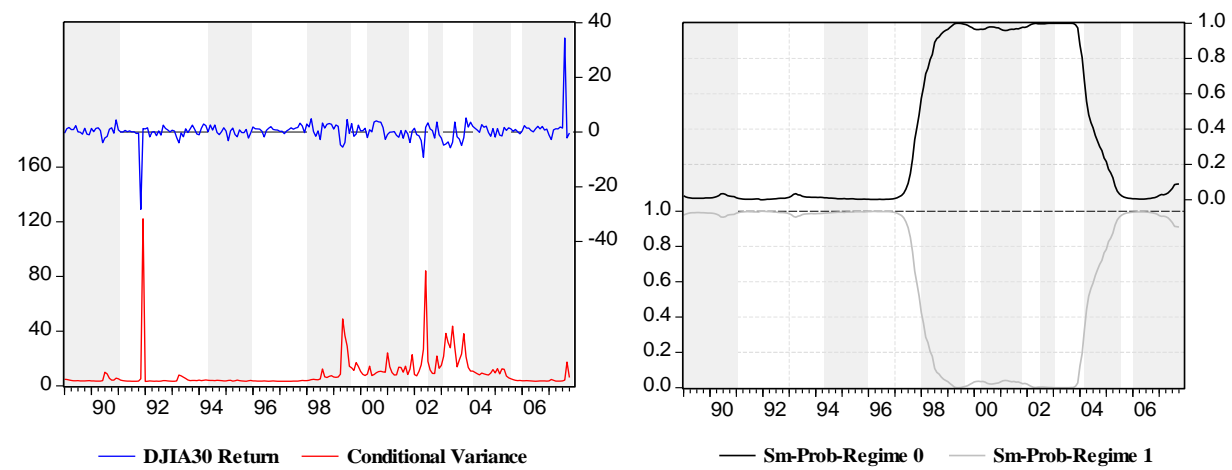

(A) United States of America 

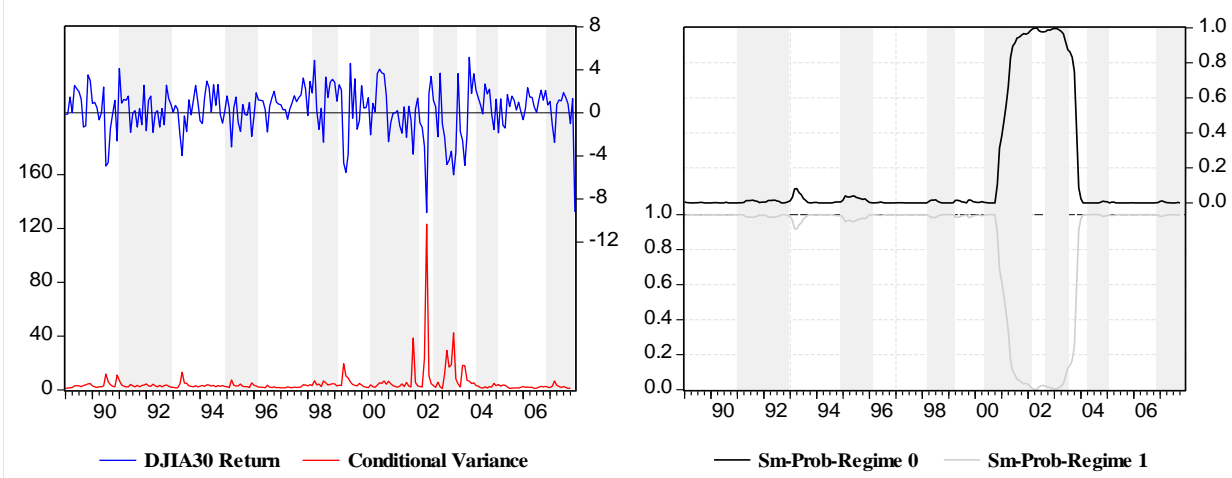

(B) Germany

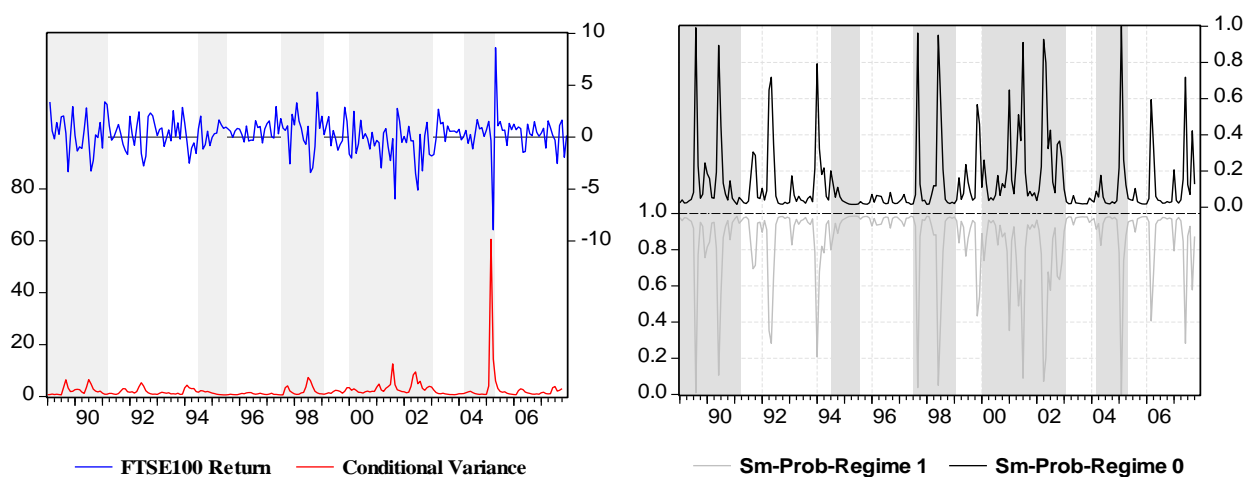

(C) United Kingdom
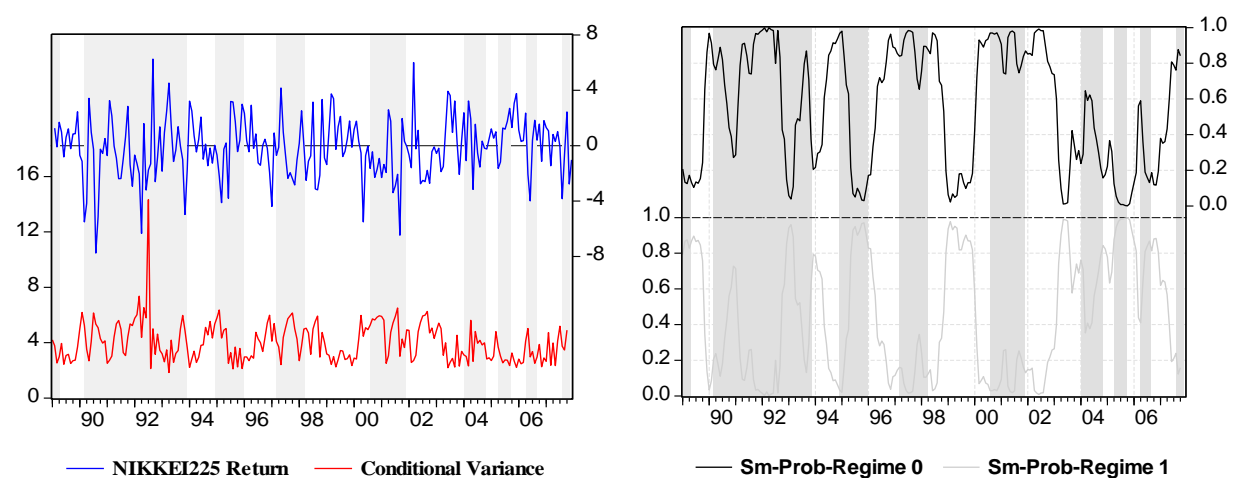

(D) Japan
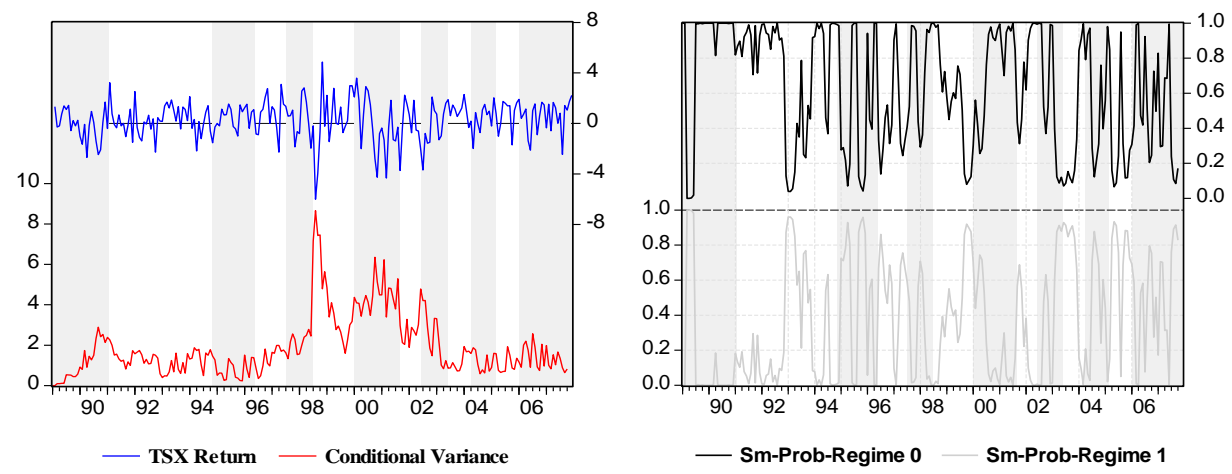

(E) Canada 


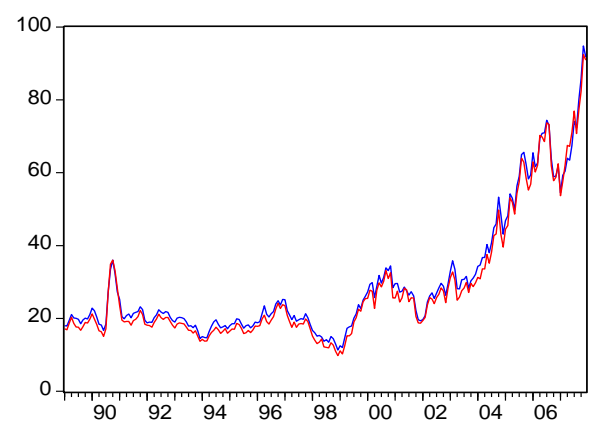

— WTI crude oil price — BRENT crude oil price

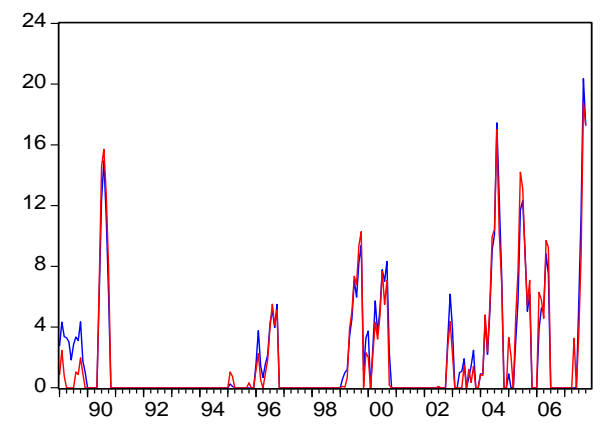

- NOPI-WTI NOPI-BRENT

Figure 1

(F) Crude oil in dollars per barrel

\section{Dynamics of month returns, conditional variances and smoothed probabilities}

The left vertical panel (A-E) shows the monthly stock market returns together with the conditional variances obtained from the MS-EGARCH model without oil shocks. The right vertical panel (A-E) displays the smoothed probabilities of regime 0 (low-mean and high-volatility regime) and of regime 1 (high-mean and low-volatility regime) at time $t$. The panel (F) shows the monthly WTI and Brent crude oil prices as well as their associated NOPI measures. The shaded vertical bars indicate the growth cycle recessions as dated by the Economic Cycle Research Institute. The sample period runs from January 1989 to December 2007 with a total of 228 monthly observations.

The panels (A-E) of Figure 1 show the smoothed probabilities that stock market returns stay either in bear regime or in bull regime. We clearly find evidence of dynamic transition between the high and low volatility regimes. In particular, periods of high volatility in three out of the five countries examined (Canada, Japan and the United Kingdom) show a relatively strong coincidence with the country-specific growth rate cycle chronologies provided by the Economic Cycle Research Institute (ECRI) over the period 1989-2007 (i.e., shaded areas in the associated graphs). ${ }^{5}$ The coincidence between the high-volatility regime and economic recessions seems to be very frequent for Canada and Japan. The high-volatility regime in the UK stock market is almost related to the recession periods around the end of 1980 s, the Asian financial crisis, and the 2000-2002 dot-com bubble. Interestingly, the estimated smoothed probabilities for U.K. are comparatively the closest. The conditional variance of this market reaches its maximum peak value together with the lowest return value during 2005. This dramatic fall in the FTSE 100 returns (8.92\%) seems to be affected by 2004-2005 energy crisis and the U.K. pension crisis in $2005 .{ }^{6}$ Overall, the UK stock market shows small increases in volatility but strong falls in returns. This could be justified by the plots of the smoothed probabilities where several periods of "low mean-high variance" states are clearly

\footnotetext{
${ }^{5}$ ECRI has established growth rate cycle chronologies for more than 20 countries and they are especially relevant to cyclical fluctuations in securities markets. See ECRI's website for more details regarding the construction methods of peak and trough dates for the growth cycles.

${ }^{6}$ The UK banking losses may be responsible for the turmoil in the stock market, forcing catastrophic losses in pension funds. According to the Association for Payment Clearing Services (APACS), many UK banks were experienced significant losses due to rising levels of fraud. Indeed, fraud losses almost doubled from $£ 12.2$ million to $£ 23.2$ million between 2004 and 2005).
} 
detected. The bear regime is frequent, but short-lived (about 1 month) as compared to the duration of economic recession phases identified by the ECRI, which appears to be much fewer and longer-lasting. The longest period of bear market in the United Kingdom took place during the 2000-2002 dot-com bubble.

The patterns of transition probabilities in the US and German stock markets are much different from the others. They experienced a single and significant bearish phase over a long period of time (from March 2001 to April 2004 for Germany and from January 1998 to October 2003 for the United States). The advent of the bear regime in these countries is likely to coincide with the Asian financial crisis, the stock market bubble of 1999/2000 as well as the terrorist attack of 2001. Afterwards, these markets enter into the bull regime.

Overall, the findings from the baseline model without the oil price effects seem to be consistent with previous research. For instance, Qiao (2008) and Jammazi and Aloui (2010) find that the stock markets in Canada, Japan and the United States, among others, were very volatile following the collapse of the dot-com bubble in 1999, and that they then switched gradually to a lower volatility regime.

\subsection{The impact of oil price shocks on stock market cycles}

Miller and Ratti (2009) suggest that the presence of several stock market and/or oil price bubbles may be responsible for the apparent weakening of the negative long-run relationship between real oil prices and real stock prices since the turn of the century. Thus, a MS-EGARCH model accounting directly for crude oil shocks is more suitable for gauging the dynamic behavior of stock market returns. Here we estimate a MS-EGARCH $(1,1)$ model where the two NOPI measures constructed from the WTI and Brent oil prices are simultaneously introduced as exogenous variables. Our information criteria (AIC and BIC) select one lag for both NOPI variables. We maintain the same regime-dependent model as in the previous section and allow the coefficients associated with NOPI variables to switch between the two states.

The estimation results are reported in Table 2. Compared to those in Table 1, we first observe an increase in the log-likelihood ratios for all cases, except for the TSX (about 7.5 points for NIKKEI225, 3 points for DJIA and DAX30, and 2.5 points for FTSE100). The extended MS-EGARCH models thus perform better than the baseline models without oil price shocks. The Box-Pierce statistics indicate no serial correlation either in the estimated residuals $(\mathrm{Q})$ or the estimated squared residuals $\left(\mathrm{Q}^{2}\right)$, suggesting the suitability of the fitted models. 
A look at the estimated coefficients shows evidence of two distinct regimes for each of the stock markets under consideration. When the effects of oil shocks are accounted for, the expected durations of bear and bull market periods decline sharply in the United States (20 and 14 times lower than those of the baseline model in Table 1) and Germany (8 and 3 times lower than those of the baseline model in Table 1). For the UK stock market, the expected duration of bear market remains the same, but that of the bull market declines. In Japan and Canada, the expected duration of both bear and bull markets increased. These findings suggest that the stock markets in the United States, Germany and to some extent the United Kingdom may take a shorter time to recover from a bear period caused by an oil price shock. The effectiveness of monetary policies may be behind this ability to react to negative shocks. Kollias et al. (2011) also find that the oil-stock relationships for United States and United Kingdom seem to be neutral during the terrorist incidents during the period 1988-2008 and explain this result by the superior efficiency of the UK and US stock markets in absorbing the impact of political events.

With regard to the coincidence between economic recession phases (or cyclical fluctuations in stock markets) and NOPI shocks, Figure 1 shows that the oil crises caused by the first Gulf war, East Asian currency crisis as well as by a set of geopolitical events coupled with natural disasters (e.g., hurricane Katrina, the North Korean missile test, conflict between Israel and Lebanon, worries over Iranian nuclear powers) seem to be associated with the 1990-1991, 1996 and 2004-2006 stock market crashes for Japan and Canada. On the other hand, oil shocks caused eventually by the 2000-2001 US energy crisis owing to manipulation by electricity producers including Enron and Reliant Energy appear to coincide with the US, UK and Canadian bear markets during 1999-00. Aside from these events, bear markets occurred during the oil price surge associated with the 2003 invasion of Iraq are also delineated in the case of the US, Germany and Japan. The remaining periods of oil crisis may affect the stock market returns but not strong enough to derail their robust recovery (Hamilton, 2004).

Table 2

Estimation results of the extended MS-EGARCH(1,1) model with oil price effects

\begin{tabular}{|c|c|c|c|c|c|}
\hline & DJIA & Dax30 & NIKKEI225 & TSX & FTSE100 \\
\hline \multirow{2}{*}{$\mu_{0}$} & $-1.6174^{* * *}$ & $-4.21957^{* * * *}$ & $-0.916^{* * *}$ & $-0.24262^{* * * *}$ & 0.1415 \\
\hline & $(-403.3)$ & $(-7.57)$ & $(-2.735)$ & $(-6.461)$ & $(0.516)$ \\
\hline \multirow{2}{*}{$\mu_{1}$} & $0.93217^{* * * *}$ & $0.68116^{* * *}$ & $0.829^{* * * *}$ & $1.15565^{* * *}$ & $0.547^{* * *}$ \\
\hline & $(5.146)$ & (5.098) & (3.377) & $(10.22)$ & $(2.277)$ \\
\hline \multirow{2}{*}{$\omega_{0}$} & $1.92931^{* * * *}$ & $1.41098^{*}$ & $2.034^{* * * *}$ & $5.8677^{* * *}$ & 0.81742 \\
\hline & $(2,162)$ & $(1,580)$ & $(6.158)$ & (10.5401) & $(1,056)$ \\
\hline \multirow{2}{*}{$\omega_{1}$} & 0.30849 & 0.39394 & $1.149^{* * * *}$ & $0.87064^{* *}$ & 0.37366 \\
\hline & $(0.2986)$ & $(0,7043)$ & $(5.599)$ & $(2.0447)$ & $(0,614)$ \\
\hline$\varphi_{0}$ & $0.85945^{*}$ & $0.73752^{* * *}$ & 0.111 & $1.16107^{* * *}$ & $0.74166^{*}$ \\
\hline
\end{tabular}




\begin{tabular}{llllll} 
& $(1.597)$ & $(2.234)$ & $(0.204)$ & $(9.398)$ & $(1.63)$ \\
$\varphi_{1}$ & $1.06199^{* * *}$ & $1.11557^{* * *}$ & $-0.802^{* * *}$ & $-0.74204^{* * *}$ & 0.15666 \\
$\beta_{0}$ & $(20.403)$ & $(11.262)$ & $(-3.104)$ & $(-2.69)^{* * *}$ & $(0.528)$ \\
$\beta_{1}$ & $-0.39203^{* * *}$ & 0.21307 & 0.398 & $0.97914^{* * *}$ & $0.54118^{* * *}$ \\
& $(-3.61)$ & $(1.143)$ & $(1.068)$ & $(86.268)$ & $(3.077)$ \\
$\delta_{0}$ & $0.95938^{* * *}$ & $0.86041^{* * *}$ & $-0.879^{* * *}$ & $-0.82775^{* * *}$ & -0.14453 \\
$\delta_{1}$ & $(33.254)$ & $(10.292)$ & $(-7.719)$ & $(-5.315)$ & $(-0.573)$ \\
& $-0.97497^{* * *}$ & 0.93251 & 0.325 & -0.07175 & -1.75244 \\
$\lambda_{W, 0}$ & $(-23.722)$ & $(0.467)$ & $(0.469)$ & $(-0.14)$ & $(-0.46)$ \\
$\lambda_{W, 1}$ & $0.82441^{* *}$ & -0.16608 & -2.096 & -0.75927 & -0.04743 \\
$\lambda_{B, 0}$ & $(1.706)$ & $(-0.551)$ & $(-0.674)$ & $(-0.403)$ & $(-0.069)$ \\
$\lambda_{B, 1}$ & 0.42582 & $0.90425^{* * *}$ & -0.278 & -0.17565 & $-0.85605^{*}$ \\
$\theta_{0}$ & $(0.7)$ & $(3.2)$ & $(-1.0)$ & $(-0.6)$ & $(-1.387)$ \\
$\partial_{0}$ & $0.23443^{*}$ & $0.12081^{*}$ & $-0.473^{* * *}$ & $-0.69834^{* * *}$ & $0.59209^{* *}$ \\
& $(1.5)$ & $(1.3)$ & $(-2.700)$ & $(-4.2)$ & $(2.084)$ \\
$p_{00}$ & $-1.01761^{*}$ & $-0.94505^{* * *}$ & 0.18068 & 0.20348 & $0.72856^{*}$ \\
$p_{11}$ & $(-1.4)$ & $(-2.1)$ & $(0.600)$ & $(0.7)$ & $(1.323)$ \\
Log-Likelihood & $-0.27811^{* *}$ & $-0.17394^{* *}$ & $0.38279^{* * *}$ & $0.79389^{* * *}$ & $-0.62891^{* * *}$ \\
$Q_{(12)}$ & $(-1.7)$ & $(-1.8)$ & $(2.300)$ & $(4.3)$ & $(-2.424)$ \\
$Q^{2}(12)$ & 0.42734 & -0.50494 & $-2.805^{* * *}$ & $-1.96094^{* * *}$ & -0.17464 \\
\hline & $(0,612)$ & $(-0,653)$ & $(-3.115)$ & $(-3,164)$ & $(-0,087)$ \\
& $-2.1694^{* * *}$ & $3.79493^{* * *}$ & $2.611^{* * *}$ & $1.32647^{*}$ & 0.32017 \\
& $(-2.829)$ & $(5.098)$ & $(2.675)$ & $(1.595)$ & $(0,287)$ \\
& $0.60524[2.5 \mathrm{~m}]$ & $0.62362[2.6 \mathrm{~m}]$ & $0.93158[14.6 \mathrm{~m}]$ & $0.87663[8.1 \mathrm{~m}]$ & $0.45645[1.8 \mathrm{~m}]$ \\
& $0.89747[9.7 \mathrm{~m}]$ & $0.97801[45.5 \mathrm{~m}]$ & $0.94296[17.5 \mathrm{~m}]$ & $0.79026[4.8 \mathrm{~m}]$ & $0.42064[1.7 \mathrm{~m}]$ \\
& 0.1297 & -456.161 & -480.064 & -387.153 & -396.684 \\
& 17.9304 & 15.5869 & 15.6934 & 8.2881 \\
& 6.292 & 15.6332 & 6.2523 & 21.2626 \\
\hline
\end{tabular}

Notes: This table reports the estimation results of the MS-EGARCH(1,1) model with a constant parameter $(\mu)$, and $\operatorname{ARCH}(\varphi)$, GARCH $(\beta)$ and asymmetric $(\delta)$ terms. $\lambda_{W}$ and $\lambda_{B}$ are the parameters associated with the effects of the WTI and Brent oil prices respectively. $\theta$ and $\partial$ are the parameters of the logistic function for determining the values of the transition probabilities. The t-statistics of the estimates are reported between parentheses. $Q(12)$ and $\mathrm{Q}^{2}(12)$ refer to the empirical statistics of the Ljung-Box test for autocorrelation applied to the residual and squared residuals at lag 12. Numbers in brackets represent the expected durations (expressed in months) of staying in regimes 0 and 1 .

The direct effects of NOPI variables on the regime-switching behavior of the conditional volatility, represented by the coefficients $\lambda$, differ across markets in terms of both sign and magnitude. The WTI NOPI variable has significant effect on all stock markets during the bull regime, but only two markets (Germany and the United Kingdom) during the bear regime. The impact from the Brent NOPI is significant for all stock markets during the bull regime and for three markets during the bear regime (Germany, the United States, and the United Kingdom). While the Brent NOPI tends to significantly reduce the volatility of stock markets in the United States and Germany for both regimes, the WTI NOPI raises it. For Canada and Japan, the effects of the NOPI associated with the Brent and WTI markets are respectively positive and negative. The NOPI effects are completely opposite for the United Kingdom with respect to the two oil markets and the regimes followed by stock market returns. 
It is obvious from our findings that although the level of sensitivity to oil price changes may vary across markets and regimes, rising oil prices have certain cost implications that in turn affect share prices. In our study, since sample countries are net importers of oil except for Canada, higher oil prices would drive up their production costs and particularly the cost of energy-intensive sectors such as transport and chemicals products (Kilian and Park, 2009). For instance, the transport sector consumes more than $70 \%$ of the US total consumption of crude oil. Hamilton (2009) provides evidence that the US recession of 2007-2008 is coupled with a collapse in automobile purchases, a slowdown in overall consumer spending and a sharp drop in consumer sentiment, which is exactly consistent with what happened following other historical oil shocks. Furthermore, Figure 1 reveals that the recession phases detected during 2000-2003 and 2003 respectively for the US and German markets stick perfectly to the periods of airline industry struggle with bankruptcy and persistently high cost of fuel driven usually by rising oil prices. Gong (2007) reports that 10 major US airline companies were forced to declared bankruptcy since the year of 2000 because of the soaring prices of crude oil. Some of them have recovered after filing a plan of reorganization according to Chapter 11 in the US Bankruptcy Code. On the other hand, there are, during the period 2000-2005, 50 European airline bankruptcies including two German companies (Berlin Jet and Aero Lloyd).

What we can tell from these findings is that stock markets are less affected by the increases in the price of oil during the bear market phases. This regime-asymmetric reaction to oil price increases can be explained by the reduced dependence of industrial production and various economic sectors on crude oil in times of economic recessions. In addition, whether the effects of oil shocks on stock market volatility are positive and negative should depends on the degree of reliance on imported oil, the share of the cost of oil in the income and the degree of improvement in energy efficiency of a given country. Our results finally suggest the potential of substitution between the two oil markets as we find their opposite effects on the volatility of our sample markets. Here it is worth noting that the resort to the diversification of foreign oil supply sources can lead to improve the resilience of stock markets depending on their actual regime.

The above-mentioned diversification strategy will not only secure a stable access to energy resources and guaranteeing price stability (Vivoda, 2009), but also permit to avoid rising oil price risk and political instability risk. The first risk is often due to increased taxes and royalties from oil production as well as to political intention for taking advantage of private oil holdings nationalization like the Venezuela's 2007 nationalization of Exxon's oil as- 
sets (Stanislaw, 2008). The risk of political instability in major oil-exporting countries is high and causes prolonged and massive oil supply disruptions. Examples include the Venezuelan strike of 2002, the 2003's civil unrest in Nigeria, the US military intervention in Iraq in 2003 and the oil pipeline sabotage by Sudanese rebels in 2004. Another reason is that possible serious disruptions to oil refinery operations may occur in the advent of unexpected natural disasters or fire accidents (e.g., the hurricane Katrina that heavily hit the Gulf of Mexico in 2005). They thus give incentives to an appropriate geographical diversification of oil supply sources among the world's most important oil production areas (Alaska's North Slope, the Gulf of Mexico and the North Sea of Europe). The diversification is more than necessary as the production of oil in these areas is expected to decline rapidly and the costs of oil extraction are becoming prohibitive (Vivoda, 2011). It should be noted that developed countries including the United States are seeking other "safe zones" with lower costs and focus on a diversification strategy of crude oil import sources in order to ensure long-term energy security (Jammazi, 2012).

\section{Concluding remarks}

To the extent that global investors increasingly use portfolio diversification as a strategy to minimize certain types of risk, the analysis of the relationships between oil prices and stock market returns is of paramount importance and relevance for investor's optimal asset allocation decisions. In this paper, we investigate the role of crude oil price increases in explaining the behavior of stock returns in five developed countries using a Markov-switching EGARCH model where the simultaneous effects of the NOPI variables associated with both the WTI and Brent markets are considered. This model captures some of the most important stylized facts of stock and oil return series such as persistence, asymmetry and structural change. Not only the stock markets are allowed to switch discretely between two distinct regimes (highand low-volatility regimes), but also it is possible to assess the regime dependence in the oil price impacts, volatility persistence and asymmetric responses of the stock markets to shocks.

Our results from the baseline model without oil price effects indicate that stock returns in all the considered markets exhibit a regime-switching behavior. The high-volatility regime is dominant in Canada and Japan, whereas the low-volatility regime appears is frequently observed for Germany, the United States and the United Kingdom. We further find that the highvolatility regime is associated with the economic recession periods for Canada, Japan and, to some extent, the United Kingdom. The effects of international market crashes or crises were 
shorter-lived for the United Kingdom (1 month), whereas the US and German stock markets experienced a single crash over a long period of time (3 to 6 years). The latter occurred at the time of the 1998-2004 economic slowdown and recessions.

The extended MS-EGARCH model that accounts for the joint effects of the two NOPI measures provides several insightful results. Similar to the baseline model, we find that the conditional volatility of the studied stock markets is regime-dependent, but its responses to oil price shocks are not the same. In general, stock market volatility is found to be less dependent on the increases in the price of oil during the bear market phases and the sign of oil price effects depends on the degree of reliance on imported oil, the share of the cost of oil in the income and the degree of improvement in energy efficiency of a given country. The relatively opposite effects of the WTI and Brent oil markets suggest a potential of substitution between them as well as the necessity of a diversification strategy of oil supply sources. Other factors that potentially affect the sensitivity of stock markets to rising oil price include the weight of energy-based sectors in the overall market index, the dependence on imported crude oil from unstable countries, the strategic solutions adopted to eventually protect the margin profit of a given industry, and the level of encouragement and support given to oil-related industries to develop and use alternative and sustainable energy sources. Our framework can be extended to investigate whether a rise in the price of crude oil leads to increase the probability of being in the bear market period by letting the transition probabilities be a function of NOPI measures.

\section{References}

Basher, S., Sadorsky, P., 2006. Oil price risk and emerging stock markets. Global Finance Journal 17, $224-251$.

Al Janabi, M.A.M., Hatemi, J.A., Irandoust, M., 2010. An empirical investigation of the informational efficiency of the GCC equity markets: evidence from bootstrap simulation. International Review of Financial Analysis 19, 47-54.

Aloui, C., Nguyen, D.K., Njeh, H., 2012. Assessing the impacts of oil price fluctuations on stock returns in emerging markets. Economic Modelling 29, 2686-2695.

Apergis, N., Miller, S.M., 2009. Do structural oil-market shocks affect stock prices? Energy Economics 31, 569575.

Arouri, M., Jouini, J., Nguyen, D.K., 2011. Volatility spillovers between oil prices and stock sector returns: implications for portfolio management. Journal of International Money and Finance 30, 1387-1405.

Arouri, M., Nguyen, D.K., 2010. Oil prices, stock markets and portfolio investment: evidence from sector analysis in Europe over the last decade. Energy Policy 38, 4528-4539.

Bachmeier, L., 2008. Monetary policy and the transmission of oil shocks. Journal of Macroeconomics 30, 17381755 .

Balke, N., Brown, S., Yucel, M., 2009. Oil price shocks and U.S economic activity: An international perspective. Energy Journal 23, 27-52. 
Bjørnland, H.C., 2009. Oil price shocks and stock market booms in an oil exporting country. Scottish Journal of Political Economy 56, 232-254.

Blanchard, O.J., Gali, J., 2007. The macroeconomic effects of oil price shocks: why are 2000s so different from the 1970s? National Bureau of Economic Research, Working Paper 13368.

Bollerslev, T.P., 1987. A conditional time series model for speculative prices and rates of returns. Review of Economics and Statistics 69, 524-554.

Boyer, M.M., Filion, D., 2007. Common and fundamental factors in stock returns of Canadian oil and gas companies. Energy Economics 29, 428-453.

Cai, J., 1994. A Markov model of unconditional variance in ARCH. Journal of Business and Economic Statistics $12,309-316$.

Chang, K.L., 2009. Do macroeconomic variables have regime-dependent effects on stock return dynamics? Evidence from the Markov regime switching model. Economic Modelling 26, 1283-1299.

Chang, K-L., 2012. Volatility regimes, asymmetric basis effects and forecasting performance: An empirical investigation of the WTI crude oil futures market. Energy Economics 34, 294-306.

Chkili, W., Aloui, C., Omar, M., John, F., 2011. Stock market volatility and exchange rates in emerging countries: A Markov-state switching approach. Emerging Markets Review 12, 272-292.

Chu, C.S.J., Santoni, G.J., Liu, T., 1996. Stock market volatility and regime shift in return. Information Science 94, 179-190.

Ciner, C., 2001. Energy shocks and financial markets: nonlinear linkages. Studies in Nonlinear Dynamics and Economics 5, 203-212.

Cologni, A, Manera, M., 2008. Oil prices, inflation and interest rates in a structural cointegrated VAR model for the G-7 countries. Energy Economics 38, 856-888.

Cologni, A, Manera, M., 2009. The asymmetric effects of oil shocks on output growth: a Markov-switching analysis for G7 countries. Economic Modeling 26, 1-29.

Cong, R.C., Wei, Y.M., Jiao, J.L., Fan, Y., 2008. Relationships between oil price shocks and stock market: An empirical analysis from China. Energy Policy 36, 3544-3553.

Diamantis, P.F., 2008. Financial liberalization and changes in the dynamic behaviour of emerging market volatility: evidence from four Latin American equity markets. Research in International Business and Finance 22, 362377.

El-Sharif, I., Brown, D., Burton, B., Nixon, B., Russel, A., 2005. Evidence of the nature and extent of the relationship between oil prices and equity values in the UK. Energy Economics 27, 819-830.

Fong, W.M., See, K.H., 2002. A Markov switching model of the conditional volatility of crude oil futures prices. Energy Economics 24, 71-95.

Gong, S.X.H., 2007. Bankruptcy protection and stock market behaviour in the US airline industry. Journal of Air Transport Management 13, 213-220.

Hamilton, J.D., 1983. Oil and the macroeconomy since World War II. Journal of Political Economy 91, 228-248.

Hamilton, J.D., 1989. A new approach to the economic analysis of nonstationary time series and the business cycle. Econometrica 57, 357-384.

Hamilton, J.D., 1996. Specification testing in Markov-switching time series models. Journal of Econometrics 70, $127-157$.

Hamilton, J.D., 2003. What is an oil shock? Journal of Econometrics 113, 363-398.

Hamilton, J.D., 2004. Causes and consequences of the oil shock of 2004. Working Paper.

Hamilton, J.D., 2009. Causes and Consequences of the Oil Shock of 2007-08, Brookings Papers on Economic Activity 1, 215-261.

Hamilton, J.D., Susmel, R., 1994. Autoregressive conditional heteroscedasticity and changes in regime. Journal of Econometrics 64, 307-333.

Hammoudeh, S.M., Ewing, B.T., Thompson, M.A., 2008. Threshold cointegration of crude oil benchmarks. Energy Journal 29, 79-95. 
Henry, O., 2009. Regime switching in the relationship between equity returns and short-term interest rates. Journal of Banking and Finance 33, 405-414.

Hondroyiannis, G., Papapetrou, E., 2001. Macroeconomic influences on the stock market. Journal of Economics and Finance 25, 33-49.

Huang, R.D., Masulis, R.W., Stoll, H.R., 1996. Energy shocks and financial markets. Journal of Futures Markets $16,1-27$.

Jammazi, R., 2012. Oil shock transmission to stock market returns: Wavelet-multivariate Markov switching GARCH approach. Energy 37, 430-454.

Jammazi, R., Aloui, C., 2010. Wavelet decomposition and regime shifts: Assessing the effects of crude oil shocks on stock market returns. Energy Policy 38, 1415-1435.

Jones, C.M., Kaul, G., 1996. Oil and the stock markets. Journal of Finance 51, 463-491.

Kilian, L., 2008. Exogenous oil supply shocks: how big are they and how much do they matter for the U.S. economy? Review of Economics and Statistics 90, 216-240.

Kilian, L., Park, C., 2009. The impact of oil price shocks on the U.S. stock market. International Economic Review 50, 1267-87.

Kollias, C., Kyrtsou, C., Papadamou, S., 2011. The effects of terrorism and war on the oil and prices-stock indices relationship. Economics of Security Working Paper 57.

Lamoureux, C.G., Lastrapes, W.D., 1990. Persistence in variance, structural change and the GARCH model. Journal of Business and Economic Statistics 8, 225-234.

Lardic, S., Mignon, V., 2008. Oil prices and economic activity: an asymmetric cointegration approach. Energy Economics 30, 847-855.

Lee, K., Shwan, Ni., Ratti, R.A., 1995. Oil shocks and the macroeconomy: the role of price variability. Energy Journal 16, 39-56.

Maghyereh, A., 2004. Oil price shocks and emerging stock markets: A generalized VAR approach. International Journal of Applied Econometrics and Quantitative Studies 1, 27-40.

Maheu, J.M., McCurdy, T.H., 2000. Identifying bull and bear markets in stock returns. Journal of Business and Economic Statistics 18, 100-112.

Miller, J.I., Ratti, R.A., 2009. Crude oil and stock markets: stability, instability, and bubbles. Energy Economics 3, 559-568.

Mork, K.A., 1989. Oil and the macroeconomy when prices go up and down: An extension of Hamilton's results. Journal of Political Economy 97, 740-744.

Mory, J.F., 1993. Oil prices and economic activity: is the relationship symmetric? Energy Journal 14, 151-161.

Nandha, M., Faff, R., 2008. Does oil move equity prices? A global view. Energy Economics 30, 986-997.

Nandha, M.S., Brooks, R., 2009. Oil prices and transport sector returns: An international analysis. Review of Quantitative Finance and Accounting 33, 393-409.

Narayan, P.K., Narayan, S., 2010. Modelling the impact of oil prices on Vietnam's stock prices. Applied Energy $87,356-361$.

Narayan, P.K., Sharma, S.S., 2011. New evidence on oil price and firm returns. Journal of Banking and Finance 35, 3253-3262.

Nelson, D.B., 1991. Conditional heteroskedasticity in asset pricing: A new approach. Econometrica 59, 347-370.

Ono, S., 2011. Oil price shocks and stock markets in BRICs. European Journal of Comparative Economics 8, 2945 .

Papapetrou, E., 2001. Oil price shocks, stock market, economic activity and employment in Greece. Energy Economics 23, 511-532.

Park, J., Ratti, R.A., 2008. Oil price shocks and stock markets in the U.S. and 13 European countries. Energy Economics 30, 2587-2608. 
Qiao, Z., Smyth, R., Wong, W.K., 2008. Volatility switching and regime interdependence between information technology stocks 1995-2005. Global Finance Journal 19, 139-156.

Sadorsky, P., 1999. Oil price shocks and stock market activity. Energy Economics 21, 449-469.

Sadorsky, P., 2008. Assessing the impact of oil prices on firms of different sizes: it's tough being in the middle. Energy Policy 36, 3854-3861.

Sari, R., Hammoudeh, S., Soytas, U., 2010. Dynamics of oil price, precious metal prices, and exchange rate, Energy Economics 32, 351-362.

Stanislaw JA, 2008. Power Play - Resource nationalism, the global scramble for energy, and the need for mutual interdependence. Deloitte Center for Energy Solutions.

Turner, M.C., Startz, R., Nelson, C.F., 1989. A Markov model of heteroskedasticity, risk, and learning in the stock market. Journal of Financial Economics 25, 3-22.

Vivoda V., 2009. Diversification of oil import sources and energy security: A key strategy or an elusive objective? Energy Policy 37, 4615-4623.

Vivoda V., 2011. Resource nationalism, bargaining and international oil companies: challenges and change in the new millennium. Working Paper, University of South Australia.

Vo, M.T., 2009. Regime-switching stochastic volatility: Evidence from the crude oil market. Energy Economics 31, 779-788.

Zhang, D., 2008. Oil shock and economic growth in Japan: a nonlinear approach. Energy Economics 30, 23742390 